\title{
Análisis comparado de las trayectorias estratégicas de empresas siderúrgicas latinoamericanas. Desarrollo interno y contexto histórico
}

\section{Comparative Analysis of Strategies of two Latin American Steel Companies. Internal Development and Historical Context}

\author{
RITA GIACALONE \\ Universidad de Los Andes
}

\begin{abstract}
RESUMEN
Las grandes empresas latinoamericanas bajo control familiar cuentan hoy con personal profesional en cargos de dirección y cotizan acciones en la Bolsa. A este grupo pertenecen las empresas siderúrgicas Hylsa/Hylsamex del Grupo Alfa (México) y Siderca (Ternium) y Siderar (Tenaris) de la Organización Techint

(Argentina). Ellas aplicaron distintas estrategias, a lo largo de décadas, hasta que, en 2005, Techint adquirió a Hylsamex y la incorporó a su transnacional Ternium. Como estas estrategias divergentes - abandono de la producción de acero por parte de Alfa y mayor concentración, por Techint- se aplicaron en el mismo contexto sectorial, se explora que rol jugaron en ellas las trayectorias históricas de ambas empresas/ grupo, en las cuales destacan su desarrollo interno y su interacción con el entorno nacional. Se utiliza como metodología el análisis histórico comparado para contrastar trayectorias estratégicas y contextos históricos.
\end{abstract}

PALABRAS CLAVE: Empresas/Grupo, Latinoamérica, Acero, Estrategias Códigos JEL: N86, N16, N66, L21
ABSTRACT

Large Latin American companies which remain under family control increasingly employ professionals at the executive level and have part of their capital in the stock market. This is the case of Hylsa/Hylsamex, property of the Alfa Group (Mexico), and of Siderca (Ternium) and Siderar (Tenaris) belonging to Techint (Argentina). They followed similar and different strategies along the last decades, until in 2005 Techint acquired Hylsamex and integrated it into its transnational Ternium. These divergent strategies - Alfa abandoned steel production, while Techint concentrated on it - have taken place within the same sector context, so this article explores the role played in these decisions by their national contexts and their own internal development. Comparative historical analysis is used in order to contrast strategies and national contexts.

KEY WORDS: Companies, Latin America, Steel, Strategies

JEL Codes: N86, N16, N66, L21 


\section{Introducción}

$\mathrm{E}$ análisis de la trayectoria estratégica de grandes empresas brinda la oportunidad de observar fenómenos de la historia económica desde una perspectiva diferente a la tradicional. Al enfocar la atención sobre las estrategias de las empresas para enfrentar coyunturas globales similares, dentro de contextos nacionales distintos y partiendo de distintas bases de desarrollo interno, se enriquece la percepción de la interrelación estrategias, agentes económicos y coyuntura histórica. La evolución de empresas del mismo sector, propiedad de grupos económicos latinoamericanos, permite verificarlo ya que sus estrategias se dan en una misma coyuntura sectorial, mostrando la importancia de su posición en el contexto nacional y de sus desarrollos internos.

Este artículo analiza el proceso de surgimiento y evolución de empresas de origen familiar del sector siderúrgico latinoamericano, a fin de comparar sus trayectorias estratégicas y explicar las razones que las llevaron a aplicar estrategias similares y distintas. La empresa, para ingresar y desarrollarse en el mercado nacional, regional y mundial, toma decisiones para competir con otros, adaptarse a condiciones cambiantes y planificar su gestión y su estructura organizativa ${ }^{1}$. El análisis de sus trayectorias estratégicas, en base a fuentes primarias y secundarias, muestra como se combinan las características propias y las circunstancias históricas (sectoriales y nacionales) para convertir la necesidad en una oportunidad de crecimiento $^{2}$. El aporte de este artículo se encuentra en la perspectiva comparativa utilizada y en la discusión de elementos del enfoque de Alfred Chandler sobre historia de empresas.

Según Chandler, las empresas se rigen por la inercia hasta que presiones externas las obligan a cambiar de estrategias, para asegurar su estabilidad y crecimiento a largo plazo; esto produce también cambios en su estructura interna. La revolución en transporte y comunicaciones de fines del siglo XIX alteró la producción y distribución para las empresas industriales que desarrollaron economías de escala (mediante nuevas tecnologías y nuevos mercados) e invirtieron en redes de mercadeo y en reclutar y entrenar gerentes. Como consecuencia, las empresas emplearon estrategias defensivas (integración horizontal y vertical) y expansivas (expansión geográfica y creación de nuevos productos tecnológicos). La complejidad que alca-

[Fecha de recepción del original, 18 de agosto de 2008. Versión definitiva, 20 de marzo de 2009].

Salas-Porras (1998), p. 134.

2 Se utiliza informes anuales de empresas, declaraciones en prensa, estadísticas oficiales, artículos en Acero Latinoamericano, órgano del Instituto Latinoamericano del Fierro y el Acero (ILAFA), y en Boletín Informativo Techint, páginas de internet y periódicos especializados en negocios. No se incluye material nuevo acerca de las empresas en sus primeras décadas, porque no se busca presentar una visión alternativa de su desarrollo histórico sino enfocarlo desde otra perspectiva. 
nzaron determinó cambios en su estructura interna, con lo cual la gerencia desplazó de la toma de decisiones a la familia propietaria. La estrategia es la variable independiente de su libro Strategy and Structure (1962) y determina los cambios que Chandler señala en The Visible Hand (1977). En otro libro, Scale and Scope (1990), él aplica en distintos contextos su interpretación, desarrollada a partir de la experiencia estadounidense, y encuentra la mayor desviación en Gran Bretaña, donde persiste el control familiar ${ }^{3}$. A este factor Chandler atribuye la pérdida de mercados y competitividad de sus empresas frente a las estadounidenses y alemanas.

Aquí se considera, sin embargo, que la estrategia es una variable dependiente de las características adquiridas por la empresa en su desarrollo y de su combinación con el contexto histórico ${ }^{4}$. De esta forma, las estrategias responden a presiones externas pero tamizadas por el desarrollo interno de la empresa a lo largo de su historia. En cuanto a los aspectos negativos que Chandler asocia con la persistencia del control familiar en la dirección de empresas, las estudiadas en este trabajo no los reflejan.

La metodología utilizada es la de estudios de caso "comparables" (similares en categorías importantes pero distintos con respecto a una o dos variables) dentro de una misma área geográfica y cultural (Lijphart, 1988). Skocpol y Somers destacan la existencia de tres lógicas en la historia comparada - la del análisis macro-causal (comprueba múltiples hipótesis en forma similar al análisis multivariado), la de la demostración paralela (analiza varios casos para comprobar que una hipótesis es válida en todos) y la del contraste de contextos (enfatiza que casos que parecen similares tienen diferencias) ${ }^{5}$. Todas son compatibles con distintos enfoques teóricos, lo que permite combinarlas. Este artículo combina la lógica paralela — cuestiona un mismo aspecto teórico en más de un caso- y el contraste de contextos. Se emplea la definición de estrategia de Chandler, como el conjunto de decisiones que determinan objetivos a largo plazo de las empresas, para asegurar su estabilidad y crecimiento mediante cambios o nuevos énfasis ${ }^{6}$.

En las dos secciones siguientes, se analizan tres empresas pertenecientes a dos grupos empresariales familiares - Hylsamex (aceros planos) del Grupo Alfa (México) y Siderca (tubos de aceros) y Siderar (aceros planos) de la Organización Techint (Argentina), desde su creación hasta la fecha. Este análisis longitudinal de su evolución trata de identificar los principales momentos de inflexión y las estrategias aso-

3 Existe control familiar cuando la familia del fundador y sus asociados cercanos poseen la mayoría de las acciones e intervienen en la dirección de la empresa.

4 Dal Bó y Kosacoff (1998), pp. 142-143, señalan que "el modo en que un agente se comporta puede cambiar... en función del entorno en el que se encuentra y de sus acciones pasadas".

Skocpol y Somers (1994), pp. 73, 82-83.

Chandler (1962), p. 174. 
ciadas con ellos. En la sección III, se aplica el análisis transversal (entre casos) para ver con mayor claridad la inter-relación entre estrategias, contexto e historia previa de cada empresa. La adaptación de las empresas a las condiciones del entorno constituye un esfuerzo consciente y deliberado, que se condensa en la estrategia y se resume en la pregunta ¿qué variables, frente a una misma situación sectorial, explican la adopción de estrategias divergentes por parte de empresas similares?

Las empresas seleccionadas pertenecen a grandes grupos económicos que continúan bajo control familiar, aunque incluyen personal profesional en cargos de dirección y cotizan parte de sus acciones en la Bolsa de Valores. Las empresas siderúrgicas Hylsamex de Alfa y Siderca y Siderar de Techint aplicaron distintas estrategias, a lo largo de décadas, hasta que, en 2005, Techint adquirió a Hylsamex y la incorporó a su transnacional Ternium. Se aseguró así acceso a materia prima y la posibilidad de producir bienes con mayor valor agregado para el mercado de EE.UU., con una estrategia de mayor concentración en el sector siderúrgico. Por su parte, Alfa se deslastró de una empresa productora de un commodity, que sufre vaivenes cíclicos, para concentrarse en otras que producen bienes con mayor valor agregado y mayor complejidad técnica ${ }^{7}$. Como estas estrategias divergentes se dieron en el mismo contexto sectorial global, la hipótesis es que fueron resultado de las trayectorias estratégicas de ambas empresas/grupos, en las cuales fueron determinantes aspectos internos y otros derivados de su interacción con el entorno nacional ${ }^{8}$.

\section{Origen y evolución histórica de Hylsamex/Alfa}

Durante la segunda guerra mundial el Estado mexicano estableció una siderúrgica con apoyo del Eximbank de EE.UU., para paliar las dificultades en la importación de acero estadounidense desde que el segundo ingresara en la guerra ${ }^{9}$. También el sector privado se interesó en la producción siderúrgica debido a que contaba con dos ventajas: 1) la existencia de mineral de hierro en México y 2) el apoyo financiero estatal para la industria, a través de Nacional Financiera (Nafinsa) ${ }^{10}$.

En 1942, a partir de capitales de las empresas Cervecería Cuauhtémoc y Vidriera Monterrey, se estableció Hojalata y Lámina, S.A. (Hylsa) en Monterrey, para fabri-

\footnotetext{
$7 \quad$ El acero común es un producto industrial dependiente de recursos naturales y con tecnología baja, lo que lo acerca a un commodity (insumo), "Siderurgia en...", (2003), p. 9.

8 Indica grupos con control familiar que nacieron de "empresas-madre", Cerutti (2000), p. 159, y que las estrategias en momentos de inflexión son producto del grupo más que de la empresa individual.

Toledo Beltrán y Zapata (1999), Vol. 1, pp. 14-15.

Rueda Peiró (1994), p. 41.
} 
car el material de las tapas de hojalata que se utilizaba en las botellas de cerveza ${ }^{11}$. Para los años cuarenta las familias propietarias, Sada Muguerza y Garza Sada, tenían una larga historia de cooperación en actividades industriales y comerciales desde fines del siglo XIX. En 1936 habían creado el Grupo VISA (Valores Industriales, S.A.), conocido antes como Grupo Monterrey ${ }^{12}$. Entre 1943 y 1945 Hylsa laminaba planchón importado, pero luego de la instalación de un horno eléctrico comenzó a producir acero ${ }^{13}$. Desde el fin de la guerra, Hylsa se expandió estableciendo vínculos con empresas industriales (automotrices, electrodomésticos, etc.) y aprovechando el apoyo estatal a la industria (aranceles altos, exenciones o reducciones fiscales, precios especiales en combustible y transporte ferroviario) y una reducida inflación entre 1954 y $1970^{14}$.

En los cincuenta, Hylsa desarrolló una tecnología de reducción directa de hierro (Hyl), para enfrentar los cuellos de botella que tenía la empresa, ya que los equipos y tecnologías importados de EE.UU. durante la guerra habían quedado obsoletos. Con un préstamo del Eximbank y la emisión de acciones, se adquirió maquinaria moderna y se desarrollaron estudios técnicos que culminaron en la creación de Hyl (1957), que adquirió su patente internacional ese mismo año. Esta tecnología e inversiones previas en la exploración de mineral de hierro hicieron que, entre 1958 y 1960, Hylsa produjera en promedio 250 toneladas de hierro esponja al día para abastecerse a si misma y a otras empresas siderúrgicas. En 1967 se vendió la primera planta HyL en México y, en 1971, en el exterior ${ }^{15}$. Para 1980 los derechos para utilizar el sistema se habían vendido en 50 países. De esta manera, las primeras exportaciones de Hylsa fueron de servicios tecnológicos. En los sesenta y setenta, Hylsa prosiguió su proceso de modernización y expansión con financiamiento extranjero, estableciendo plantas fuera de Monterrey y agregando una planta de peletización (1970). También comenzó a exportar tubos con costura, pero sólo exportó lámina en forma constante desde $1971^{16}$.

En 1973 fue asesinado en un intento de secuestro Eugenio Garza Sada, líder de VISA. Su muerte abrió las puertas a la reestructuración del grupo propietario de Hylsa, que se organizó como holding (corporación con actividades diversificadas) y,

11 Toledo y Beltrán (1999), T.1, pp. 18, 201 y 205; Cerutti (2000), pp. 162-163. Previamente, éstas se fabricaban con material importado de EE.UU., pero la guerra obstaculizó su importación por la necesidad de surtir de acero a la industria armamentista.

12 Flores (2000), pp. 125-126; Guzmán (2002), pp. 206-207.

13 Toledo y Beltrán (1999), T.1, p. 217.

14 Pueda Peiró (1994), p. 41.

15 Toledo Beltrán y Zapata (1999), T. 1, pp. 22, 325-326; T. 2, pp. 74, 81, 326. Hyl atraía a países en desarrollo por sus costos de inversión bajos, poco consumo de energía y fácil operación y mantenimiento, Guzmán (2002), p. 379.

16 Toledo Beltrán y Zapata (1999), T. 2, p. 83. Hasta los sesenta, las exportaciones de acero fueron controladas por el gobierno mexicano para abastecer al mercado nacional. 
en 1974, se dividió en el Grupo Alfa y el Grupo Visa ${ }^{17}$. El primero, bajo dirección y control de la familia Garza Sada, quedó integrado por Hylsa, Empaques de Cartón Titán y 25\% de las acciones de Televisa, que luego se convirtieron en divisiones (Alfa Acero, Alfa Papel y Empaque y Alfa Industrias), de las cuales la primera era la más importante ${ }^{18}$. Este cambio en su estructura indica la continuidad del carácter familiar de la empresa. Al ser creado, Alfa era el mayor grupo privado de México, con activos por más de 500 millones de dólares y casi 9.000 trabajadores.

En los setenta, la siderurgia mundial sufrió una desaceleración de la demanda, afectada por los problemas creados por el alza de los precios del petróleo y la competencia de materiales sustitutos (plástico, aluminio, etc.) y, en los ochenta, entraron al mercado mundial del acero Brasil, Corea y China, países de industrialización reciente. Al caer los precios del acero, las empresas de países desarrollados aumentaron sus compras de acero común a otros países, para reducir costos en instalaciones e importaciones de mineral de hierro y disminuir problemas ambientales, y algunas se especializaron en aceros especiales (inoxidables, galvanizados, etc.) con mayor valor agregado y producidos en plantas pequeñas y sofisticadas (minimills) ${ }^{19}$. Esto hizo que las empresas de los países en desarrollo, que contaban con recursos naturales (hierro) y energía (gas) y/o conseguían atraer a plantas automotrices, aumentaran su producción.

Dentro de este contexto sectorial, entre 1974 y 1981, bajo la dirección de Bernardo Garza Sada, Alfa contrató préstamos nacionales y extranjeros por 2,4 billones de dólares, para adquirir empresas subsidiarias, que en 1982 pasaban de 100, y emitió numerosas acciones ${ }^{20}$. Esta estrategia tenía como objetivo contrarrestar, mediante la diversificación, el carácter cíclico de la siderurgia ${ }^{21}$. Para compensar las fases de baja, Alfa invirtió en alimentos congelados, turismo, etc., sólo o asociado con capital extranjero.

De esta forma, cuando el gobierno mexicano declaró la moratoria del pago de su deuda externa (agosto de 1982), precipitando la crisis de la deuda, el grupo estaba endeudado y la tasa de interés promedio que pagaba había aumentado $32 \%$ en un año. También lo afectó el deslizamiento de la paridad cambiaria (de 2\% en 1980 a $13 \%$ en 1981), porque el $72 \%$ de su deuda era en moneda extranjera ${ }^{22}$. Como desarrollos positivos, puede señalarse que la producción de Hylsa sobrepasó 1.500 .000 toneladas en 1979 y en 1980 sus ingenieros presentaron HyL III, que abarató el gasto en gas natural de sus plantas.

\footnotetext{
17 Hoshino (1993), p. 514; Pozas (1993); Flores (2000).

18 La tercera englobó lo que no era ni acero ni empaques, Dávila (2000). Hylsa se convirtió en la empresa madre de Alfa, con 65,9\% de sus activos, Flores y Dávila (2001), p. 99.

Guzmán (2002), pp. 70-72, 86-87.

Dávila (2000).

Garrido (1998), pp. 461-462.

Toledo Beltrán y Zapata (1999), T. 2, p. 339.
} 
La intervención del Estado mexicano salvó de la quiebra a Alfa mediante préstamos del Banco Nacional de Obras y Servicios, por 12.000 millones de pesos, con una tasa de interés fijo del 12\%, frente a la tasa promedio de $39 \%$ del resto del sistema bancario mexicano ${ }^{23}$. Tanto la importancia económica del grupo y el número de trabajadores que empleaba como sus buenas relaciones con el Presidente López Portillo (1976-1982) motivaron este tratamiento preferencial ${ }^{24}$. Esto siguió a una primera etapa de relaciones ambiguas entre el grupo y los gobiernos mexicanos, pues los empresarios regiomontanos se caracterizaron por su oposición a los gobiernos del PRI (Partido Revolucionario Institucional) pero, a la vez, se beneficiaron de las políticas industriales que esos gobiernos establecieron (aranceles altos, créditos fáciles, etc.) ${ }^{25}$.

Para enfrentar la crisis, Alfa vendió activos, redujo personal corporativo, desincorporó empresas y se concentró en sectores claves, como el acero. El gobierno exigió que el grupo capitalizara 300 millones de dólares de su deuda, aumentando su capital en un 30\%, lo que permitió que varios bancos se convirtieran en accionistas y entraran al consejo de administración del grupo ${ }^{26}$. Pero ni la crisis de la deuda ni la intervención de bancos en su capital desplazaron a la familia Garza Sada del control del grupo. Los apellidos de la familia no aparecieron en posiciones de dirección y administración del grupo hasta 1988, cuando las políticas adoptadas por el gobierno mexicano comenzaron a cambiar la situación económica del país y los ingresos por exportaciones de Hylsa aumentaron $36 \%$ con respecto al año anterior ${ }^{27}$. En ese momento, la familia recuperó poder accionario y administrativo y, en 1998, Alfa controlaba el $82 \%$ de Hylsa ${ }^{28}$.

En los ochenta, Hylsa pasó de producir para el mercado doméstico a producir para exportar, aprovechando las ventajas que otorgaban un peso mexicano y un salario real bajos ${ }^{29}$. En esa década, México ingresó al GATT, lo cual abrió la importación de acero y productos de acero, tendencia que se profundizó con la firma del TLCAN (Tratado de Libre Comercio de América del Norte, 1993), con EE.UU. y Canadá. Frente a la disminución de la demanda interna por efecto de las importaciones, las empresas siderúrgicas se asociaron con empresas estadounidenses para exportar hacia ese país, donde sus productos tienen ventajas en costos y precios ${ }^{30}$.

Toledo Beltrán y Zapata (1999), T. 2, pp. 339-340.

Hoshino (1993), pp. 532-533.

Los enfrentamientos entre Eugenio Garza Sada y el Presidente Luis Echeverría (1970-1976), luego de que el empresario pidiera la reprivatización de empresas estatales, hicieron que la Confederación Patronal Mexicana culpara al discurso anti-empresarial del gobierno por su asesinato, Puga (1993), p. 164.

26 Dávila (1997); Flores (2000), p. 210.

$27 \quad$ Alfa en los setenta estaba pasando del control familiar a una gerencia más profesional pero esto se revirtió al recuperar control del grupo después de la crisis, Hoshino (1993), p. 523.

Flores (2000), p. 214.

Grupo Industrial Alfa, 1985; Dávila (2000), p. 18; Guzmán (2002), p. 321.

Guzmán (2002), pp. 235-237, 307-309. 
Hylsa se convirtió en un productor de bajo costo para el mercado externo, de tal forma que para 1990 su producción por trabajador excedía en 65\% el promedio del sector siderúrgico mexicano ${ }^{31}$.

En 1993, cuando la dirección del grupo quedó en manos de Dionisio Garza Medina, sobrino de Bernardo Garza Sada y cuarta generación de la familia fundadora, Alfa se organizó en cuatros compañías independientes (Hylsamex, acero; Sigma, alimentos congelados; Alpek, petroquímica y Versax, diversas industrias), que cotizaban acciones en la bolsa ${ }^{32}$. Para entonces, el grupo era el segundo en exportaciones, luego de la industria automotriz La estrategia de Alfa buscaba balancear sus finanzas invirtiendo en México en todas las áreas que presentaban oportunidades, utilizando sus contactos en el exterior para coordinar asociaciones en áreas nuevas. El objetivo explícito era reducir su dependencia de los ciclos industriales mediante el aumento del número de empresas productoras de servicios o de productos de mayor valor agregado ${ }^{33}$.

Cuando una nueva crisis económica sacudió a México en 1995, el grupo se encontraba en posición más segura que en 1982, debido a las alianzas que había establecido con empresas extranjeras, las cuales facilitaron su acceso al crédito internacional. Ese año, Alfa obtuvo 610 millones de dólares en el mercado financiero internacional, lo que le permitió reducir su deuda a corto plazo, con lo cual para fines de 1995 el costo promedio de su deuda era de 10\%, igual al que tenía antes de la devaluación de diciembre de $1994^{34}$.

En 1995, Hylsamex inauguró la primera minimill para producir aceros especializados en México, pasando a exportar parte de su acero incorporado en productos mexicanos con mayor valor agregado (automotores, etc.) ${ }^{35}$. Hylsamex había aumentado sus exportaciones directas después de 1982 para repagar su deuda externa, pero, desde 1994, aumentó también sus exportaciones indirectas, mediante el acero que vendía en México para abastecer a los exportadores de productos manufacturados a EE.UU. y Canadá. Sin embargo, cuando observamos la participación de la producción de acero de la empresa dentro del total de México, ésta había disminui-

\footnotetext{
31 Snodgrass (1992), p. 10.

32 En 1996 a Alfa se agregó una compañía tenedora de acciones, Onexa, y en 1997 se organizó Alfa Apice, por encima de las empresas, propietaria y controladora de la mayoría de las acciones comunes de sus empresas y subsidiarias, Dávila (1997).

33 Pozas (1997). Garza Medina buscaba convertir a Alfa de una compañía de commodities en una compañía de productos con mayor valor agregado y mayor margen de ganancias, Halasz (1994).

34 Pozas (1997). Igualmente, tuvo que vender Empaques de Cartón Titán.

35 Alejandro Elizondo, presidente de Hylsamex, afirma que la recuperación de las ventas domésticas de acero, "no proviene de que el país esté consumiendo más sino de que nuestros clientes están manufacturando cosas que exportan", Kuster (1997). Según INEGI (1997), p. 66 y (1998) p. 119, la producción de acero mexicano creció entre 1992 y 1997 y, desde 1995, su exportación se estancó mientras aumentaba la de productos elaborados con acero.
} 
do de $27 \%$ en 1970 a $25 \%$ en $1999^{36}$. Paralelamente, Alfa pasó de ser el primer grupo económico mexicano entre 1974 y 1984, a ubicarse como tercero en 1990 y séptimo, para fines de los noventa ${ }^{37}$. Este desplazamiento se relacionó con el surgimiento de grupos nuevos, asociados a capital bancario, durante los noventa.

En 1997 Hylsamex participó en la adquisición de la Siderúrgica del Orinoco (Sidor), empresa estatal de Venezuela, con Techint y otros grupos latinoamericanos, mediante el Consorcio Amazonia. La compra de Sidor permitió a Hylsamex importar acero venezolano a precios competitivos, para abastecer de productos industriales a los mercados del TLCAN ${ }^{38}$. Previamente, había participado en licitaciones para adquirir empresas siderúrgicas mexicanas que se estaban privatizando, pero ellas fueron ganadas por otros grupos, que se fortalecieron ${ }^{39}$. Esto contribuyó para que Alfa pasara de alianzas estratégicas que atraían inversiones a México a realizar inversiones en el exterior. Para 1997, Hylsamex aportaba a Alfa el mayor porcentaje de sus ganancias totales y tenía alianzas estratégicas con empresas de Alemania, EE.UU. y Japón ${ }^{40}$.

También en los noventa, Hylsamex invirtió 1,6 billones de dólares para reemplazar 78\% de sus instalaciones con tecnología actualizada. Algunas inversiones se hicieron en asociación con empresas extranjeras, pero para fines de 1999 la empresa adeudaba 1,38 billones de dólares ${ }^{41}$. Este nuevo endeudamiento de Hylsamex para desarrollar su capacidad tecnológica buscaba enfrentar a las siderúrgicas rivales que habían privatizado empresas estatales. El éxito de Hylsa/Hylsamex estuvo ligado a su actividad tecnológica innovadora, mediante inversiones en investigación y desarrollo, y su principal desarrollo tecnológico se benefició, en los sesenta y setenta, por el precio subsidiado del gas natural, necesario para producir hierro esponja. Hylsa entró en una nueva fase de desarrollo en 1956, después de la contratación de jóvenes ingenieros egresados del Instituto Tecnológico de Estudios Superiores de Monterrey (ITESM), que combinaron sus conocimientos con la experiencia de los técnicos de la empresa y tuvieron a su disposición la nueva maquinaria adquirida ${ }^{42}$. En las décadas posteriores, Hylsa adquirió tecnología hasta 1981, para disminuir sus inversiones en este sector después de 1982 por sus problemas financieros. En los noventa, retomó las transferencias tecnológicas del exterior, pero, al mismo tiempo, entre 1969 y 1993 registró 66 patentes en EE.UU., la tercera parte de las patentes registradas por empresas mexicanas en ese país.

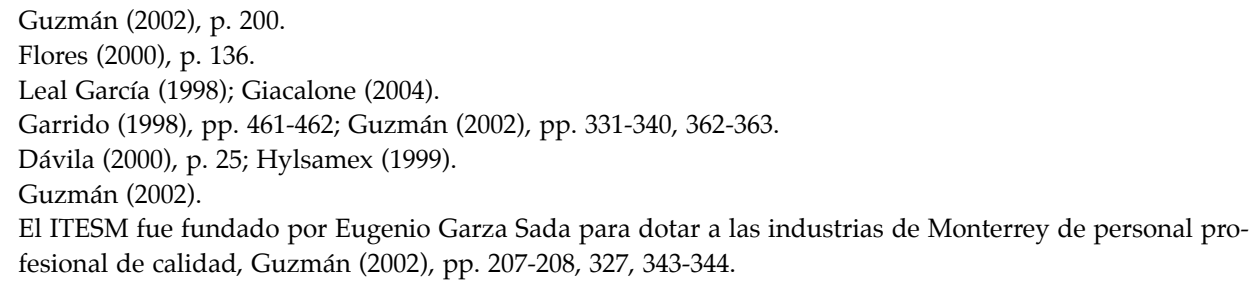


Sin embargo, en el 2000, Hylsamex cerró sus minas y algunas plantas productoras durante meses porque a su endeudamiento se agregó el alza en el precio del gas natural, un insumo que el sistema Hyl utiliza en grandes cantidades. Para entonces pagaba 7 dólares por cada millón de pies cúbicos de gas, en comparación con 2 dólares al principio del año $(65 \% \text { más })^{43}$. A comienzos del siglo XXI, la siderurgia mexicana en general enfrentaba una situación negativa ${ }^{44}$ por la sobreproducción de acero en el mercado internacional, la fortaleza del peso mexicano, el alza en los precios domésticos del gas y de la electricidad y, en Hylsamex, las deudas contraídas para adquisiciones, fusiones y asociaciones estratégicas ${ }^{45}$.

Lo anterior incidió para que Alfa enfatizara sus actividades en negocios no cíclicos, a fin de impedir el impacto negativo de las fluctuaciones internacionales del acero. Su informe del 2000 indicaba que el grupo había tenido crecimiento hasta mediados del 1999; luego la caída de los precios internacionales del acero y el aumento del precio del gas redujeron sus ingresos ${ }^{46}$. Desde entonces los esfuerzos de producción se concentraron en las líneas que aseguraban ganancias (nylon, lycra, alimentos, repuestos para automóviles), reduciendo al mínimo las inversiones en acero para reducir su deuda, con lo cual Alfa se reorientó del producto al merca$\mathrm{do}^{47}$.

El año 2004 fue positivo para Hylsamex porque sus ingresos aumentaron 57\%, lo que le permitió reducir su deuda de 1014 millones de dólares a $546^{48}$. Los problemas que la afectaron ese año fueron el alto costo de las materias primas -el precio del hierro había subido 19\% y el de los pellets, 39\% - y del gas natural. Para compensarlos, la empresa redujo costos e integró su producción, a la vez que enfatizó la investigación en una tecnología que redujera el consumo de gas para producir hierro esponja. Sin embargo, a fines del 2004 se anunció que, a pesar del aumento de sus ingresos, Hylsamex había evitado la quiebra porque Alfa había invertido en ella ganancias de otras empresas ${ }^{49}$. Esto confirmó la decisión del grupo de salir de un rubro sujeto a tantos vaivenes ${ }^{50}$. Alfa recapitalizó y reestructuró la deuda de Hylsamex, para venderla después de que el ciclo de precios negativos se reinvirtiera en 2004, lo que le permitió negociar un mejor precio con Ternium/ Techint en 2005.

\footnotetext{
Hylsamex, S.A. de C.V. (2000).

Torres (2001).

45 Un ejemplo fueron los 210 millones de dólares para pagar su participación en el Consorcio Amazonia, Dávila (1997), p. 25; El Financiero, 23/12/1997; Hylsamex (1999); Leal García (2001).

46 "Redefining..." (2006), pp. 4, 8.

$47 \quad$ Salas-Porras (1998), p. 148.

48 6/04/2005, www.hylsamex.com.mx

49 "Steelmaker Hylsamex..." (2004).

50 www.globalmanufacture.net/home/news/shares.cfm, Sept. 22, 2004.
} 


\section{Origen y evolución histórica de Siderca y Siderar/Techint}

En Argentina, Techint nació en los años cuarenta como Compañía Técnica Internacional, fundada por Agostino Rocca. Su actividad fue comercial pero se encargó del montaje técnico del primer gasoducto patagónico para encargarse luego, entre 1946 y 1955, de casi treinta obras vinculadas al petróleo, gas natural y electricidad en Argentina, Chile y Brasil. La demanda argentina de tecnología y maquinaria para el proceso de industrialización brindó a Techint la oportunidad de establecerse ${ }^{51}$.

Rocca y sus socios habían fundado en 1945, en Milán, la Compagnia Technica Internazionale con el objetivo de exportar productos, maquinarias e instalaciones fabriles italianas y ofrecer servicios técnicos de estudios, construcciones y gestión de plantas $^{52}$. Techint ofreció estos servicios en Argentina desde 1946, junto con la importación de maquinaria, mientras el grupo en Italia se concentraba en la exportación ${ }^{53}$. Rocca tenía una larga historia profesional como gerente de empresas públicas - hasta 1933 en la reestructuración de las finanzas de empresas eléctricas, telefónicas, etc. y, desde entonces, en el campo siderúrgico (Dalmine, Ansaldo, etc. ${ }^{54}$. Su experiencia le hizo comprender las oportunidades que ofrecía la fundación de una empresa siderúrgica en la Argentina de posguerra y en ella Techint invirtió los beneficios obtenidos en la construcción de gasoductos ${ }^{55}$.

Techint había proyectado una planta de tubos de acero sin costura para la empresa argentina SIAM de Torcuato Di Tella, pero éste prefirió el proyecto de una firma estadounidense. Rocca decidió entonces lanzar el proyecto en asociación con la empresa italiana Dalmine. Su planta siderúrgica (Dalmine SAFTA) se estableció en la Provincia de Buenos Aires, en 1954 y enfrentó numerosas restricciones y mecanismos burocráticos del gobierno argentino, aunque también recibió créditos del estatal Banco Industrial ${ }^{56}$. Sus tubos se vendían a la petrolera Yacimientos Petrolíferos Fiscales (YPF) pero, en los sesenta, parte de su producción se orientaba al exterior, porque producía más de lo que podía vender en Argentina.

Hasta 1969, el crecimiento de Dalmine se obtuvo reinvirtiendo la mayor parte de sus utilidades y pagando menores dividendos. Parte de lo reinvertido fue en tecnología, como en 1962 cuando se instaló Siderca, una acería eléctrica alimentada

51 Castro (2007), pp. 89-90; Lussana (1999), p. 96; Majul (1992, T. I), pp. 174-175.

52 Sus socios eran su hermano Enrico, su hijo Roberto, sus cuñados Rodolfo y Edoardo Queirazza y otros (Roberto Einaudi, Renato Pesaro, Stamaty Rodocanachi).

53 Según Roberto Rocca, Techint nació en Argentina como compañía de ingeniería para "encontrar una salida a un alto número de ingenieros y especialistas capaces y calificados, sin posibilidades de trabajo" en Italia, Ostiguy (1990), p. 223.

54 Lussana y Tonolini (2005), pp. 22-26; Castro (2003), pp. 121-126.

55 Roberto Einaudi, citado en Castro (2003), p. 139.

56 Castro (2007), pp. 90-91; Castro (2003), pp. 137-139. Ni la empresa estatal Somisa ni la planta de Siam producían tubos sin costura. 
con chatarra y una central termoeléctrica que cubrió los requerimientos de energía de Dalmine y Siderca hasta su fusión en 1964. Dalmine/Siderca se convirtió en una empresa pionera al comprar e instalar una computadora IBM en el proceso de producción de acero entre 1968 y 1969. En 1976 estableció una planta con tecnología Hyl para alimentar sus grandes hornos. Esto, así como inversiones en un horno eléctrico de gran potencia y capacidad y una planta de laminación con tecnología propia, fue dirigido por Roberto Rocca, hijo de Agostino, al hacerse cargo de Techint ${ }^{57}$.

En los sesenta, Techint desarrolló una empresa de aceros planos, Propulsora Siderúrgica. El proyecto era crear una planta siderúrgica integrada, con laminación en caliente, alto horno y acería, concentrándose en edificar un grupo industrial siderúrgico y postergando planes de diversificación ${ }^{58}$. Pero, en 1974, el gobierno le retiró la autorización para construirla a fin de proteger a Somisa, empresa siderúrgica de la Dirección General de Fabricaciones Militares ${ }^{59}$. El proyecto se redujo a una laminadora de aceros planos en frío que sufrió inconvenientes debido al cuasi monopolio estatal de la producción e importación de aceros planos. Esto hizo que se impusiera a la chapa laminada en frío un precio inferior al del mercado internacional. La exportación compensó esta situación y demostró que Propulsora fabricaba un producto con estándares internacionales ${ }^{60}$.

El boom de los precios internacionales del petróleo en los setenta alentó a Siderca a orientar sus tubos hacia el mercado externo y a invertir en nuevas tecnologías del acero, volviéndose menos dependiente de los insumos de Somisa ${ }^{61}$. En 1980 se creó Siderca International que, al inicio de la crisis de la deuda, instaló su primera oficina comercial en EE.UU. y luego otra en China. Aunque Techint fue afectado por los problemas económicos y sociales de Argentina en esos años, entre 1976 y 1988 invirtió 1.200 millones de dólares en un plan de expansión de Siderca, que aumentó sus exportaciones 16 veces $^{62}$. En general, las exportaciones siderúrgicas argentinas crecieron en los ochenta en plantas de proceso continuo, con estándares internacionales, que aprovechaban recursos locales (gas y petróleo) y sobrepasaban las posibilidades de absorción del mercado nacional ${ }^{63}$.

En 1992, Techint adquirió 69\% de Somisa y fusionó a Somisa con Propulsora Siderúrgica y otras empresas para crear Siderar. El plantel de profesionales en inge-

Aspiazu y Basualdo (1993), p. 103; Castro (2007), pp. 93-95. Hasta 1987 Siderca no recibió créditos estatales pero se benefició del régimen de promoción para empresas que instalaran o ampliaran unidades siderúrgicas, Basualdo y Aspiazu (1989), pp. 130-134.

58 Lussana y Tonalini (2005), p. 70.

59 Azpiazu y Basualdo (1993), pp. 109-110.

60 Castro (2007), pp. 98-105.

${ }^{61}$ Bisang y Chidiak (1995), pp. 6-7, relacionan la internacionalización con la crisis del sector público argentino que afectó las compras de YPF.

62 Artopoulos (2005), p. 9, citado en Castro (2007), p. 95.

63 Bisang y Kosacoff (1992), p. 92. 
niería y administración ${ }^{64}$, desarrollado para el proyecto integrado de Propulsora, que no se construyó, participó en la re-estructuración tecnológica y gerencial de Somisa y facilitó la expansión de Techint en el exterior, al reestructurar la mexicana Tamsa (Tubos de Acero de México, S.A.) y la venezolana Sidor (aceros planos), adquiridas, respectivamente, en 1993 y $1997^{65}$. Para entonces, Siderar producía acero para automotores y electrodomésticos, envases y construcción vial, entre otros rubros.

Mientras tanto, en los noventa, Siderca era la tercera planta latinoamericana en producción, después de haberse visto afectada, inicialmente, por la convertibilidad monetaria y la apertura comercial posterior a 1989. Bisang lo atribuye a una rápida "puesta al día" de su ingeniería financiera, gracias a los acervos tecnológicos y económicos acumulados en años previos, entre los que destacaban sus contactos con proveedores internacionales de tecnología y su capacidad de captar fondos en el mercado internacional ${ }^{66}$. Para 1999, luego de controlar Tamsa y adquirir 37\% de Dálmine en Italia, Techint representaba 18\% del mercado global de tubos sin costuras y $30 \%$, del de tubos petroleros ${ }^{67}$.

Techint, en esa década, invirtió en otras industrias (cerámicas, vidrios), en obras de ingeniería y construcción (gasoductos y grandes plantas industriales) y en servicios (ferrocarriles, vialidad, saneamiento y urbanización) ${ }^{68}$. Esta ampliación fue resultado de inversiones hechas a principios de la década en la privatización y re-estructuración de empresas públicas que operaban en distintos sectores (energía, teléfonos, concesión de rutas, etc.). Algunas (producción y distribución de gas y electricidad) eran auxiliares de la actividad siderúrgica y permitieron una mayor integración, mientras otras buscaban diversificar inversiones, asociándose con empresas transnacionales ${ }^{69}$. En la segunda mitad de los noventa, Techint vendió su participación en servicios públicos y abandonó su diversificación en Argentina, para consolidar sus empresas siderúrgicas y las que permitían una mayor integración (petroleras, etc.). Esto puede relacionarse con el hecho de que, a lo largo de la década, la rentabilidad del sector "Metales" en Argentina pasó de negativa (al establecerse el Plan de Convertibilidad en 1991) a ser una de las más altas en 1997, amparada por medidas antidumping del gobierno ${ }^{70}$. A partir de 1995,

$64 \quad$ Castro (2005), p. 16.

65 Kosacoff (1999), p. 133. Techint participó en la fundación de Tamsa en 1952 y aumentó su paquete accionario a lo largo del tiempo, Toledo Beltrán y Zapata (1999), T.1, pp. 229-231.

$66 \quad$ Bisang (1998), pp. 133-136.

67 Kosacoff (1999), pp. 85, 117-118, 125-126. Previamente, Siderca había adquirido SIAT, la planta de tubos con costura desarrollada por SIAM, Aspiazu y Basualdo (1993), p. 108.

68 Bisang (1998), pp. 106-107, 145. Aunque no tenía bancos, poseía compañías inversoras y de seguros, Ostiguy (1990), p. 243.

69 Aspiazu y Vispo (1994), pp. 138-139; Basualdo (2000), p. 168.

$70 \quad$ Basualdo (2000), pp. 139, 154-155, 189-190, 208. La convertibilidad favoreció inicialmente a los servicios frente a las exportaciones industriales, Kosacoff y Ramos (1998), pp. 30-31. 
cuando la industria argentina experimentó los efectos negativos del plan (desindustrialización y venta de empresas a capital extranjero), Siderca y Siderar actuaron como motores de arrastre para sus firmas proveedoras argentinas, que aumentaron producción y ventas ${ }^{71}$.

A principios de la década del 2000, las empresas siderúrgicas de Techint se organizaron en dos compañías transnacionales, Tenaris ${ }^{72}$ (productos y servicios tubulares, 2001) y Ternium (aceros planos, 2005) ${ }^{73}$. Tenaris abarcó a empresas de tubos sin costura (Dalmine, Siderca, Tamsa, NKKK Tubes, Algoma Tubes, y Tavsa) en Italia, Argentina, Japón, Canadá y Venezuela, junto con dos empresas de tubos con costura - Confab (Brasil) y SIAT (Argentina). Techint vinculó el cambio de marca de su área de tubos con un cambio de estrategia, desde una competencia basada en el mejor producto a una competencia basada en la satisfacción del cliente, maximizando el servicio del producto ${ }^{74}$. Además, integrar a Siderca y a Siderar en empresas globales, fuera de los vaivenes de la economía argentina, permitía enfrentar mejor las condiciones del entorno brindando estabilidad económica y acceso a mercados y financiamiento.

En el caso de Siderar, el default de Argentina en 2001 y el cambio de orientación económica posterior la obligaron a re-estructurar su deuda por no poder pagarla. Sin embargo, la recuperación argentina se apoyó en sectores que son grandes consumidores de aceros planos - la construcción y la industria automotriz-, permitiendo una cancelación de la deuda más rápida de lo previsto ${ }^{75}$. La devaluación que siguió al default volvió más competitivas a las exportaciones siderúrgicas ${ }^{76} \mathrm{y}$, desde 2003, Techint hizo nuevas inversiones en sus empresas (en 2006 obtuvo control mayoritario de Siderar) y compras en el exterior ${ }^{77}$.

Las motivaciones de Techint para invertir en el exterior en aceros tubulares fueron distintas a las motivaciones para invertir en el exterior en aceros planos. Mientras aquellas eran establecer una red globalizada (producción, venta, servicios técnicos y de construcción), obteniendo mayor poder en el mercado global y desarrollando mayor valor agregado, las de aceros planos buscaban conformar una compañía regional con plantas en Argentina, Venezuela y México ${ }^{78}$. Prevalecieron enton-

Milesi, Novick y Yoguel (2004), pp. 51.

Antes de 2002 funcionaba como DST (Dalmine-Siderca-Tamsa). Tenaris está incorporada en Luxemburgo y controlada por San Faustín N.V. (Antillas Neerlandesas), donde Rocca \& Partners controla buena parte del poder de voto, Tenaris Annual Report 2007 (2008), pp. 35-36.

73 Ternium (Luxemburgo) es controlada por Inversora Siderúrgica Ltd (Gibraltar), propiedad de Rocca \& Partners, Ternium Annual Report 2006 (2007), p. 107.

74 “Tenaris. El re-branding..." (2001), p. 14, incluye declaraciones de Paolo Rocca en este sentido.

$75 \quad$ Stok (2005), p. 33.

76 Declaraciones del director de fabricación de Siderca en "Tenaris invertirá..." (2003).

77 “Siderar apuesta..." (2003); “Tenaris abrirá..." (2003). “Ternium increases..." (2006).

78 Kosacoff (1999), p. 114. 
ces estrategias para incorporar mercados regionales e impedir que entraran a ellos empresas competidoras. Posteriormente, la estrategia pasó de defensiva a buscar conformar "la empresa líder del sector en toda América"79. Esto se concretó en Ternium con la adquisición de Hylsamex (2005) y el control accionario de Sidor (2006) ${ }^{80}$. A pesar del carácter cíclico del mercado internacional del acero, Hylsamex poseía ventajas porque era un complejo integrado en su cadena de valor, con minas de hierro, plantas de pellets, de productos largos, de aceros planos y de aceros recubiertos y centros de servicio y distribución en México y EE.UU. ${ }^{81}$.

La importancia de Hylsamex hizo que para comprarla Techint consiguiera créditos por 1,38 billones de dólares con bancos internacionales. Esta operación significó el regreso de un holding argentino al mercado financiero internacional luego del default de ese país. Sin embargo, Techint no hubiera podido reunir esa cantidad de no ser una transnacional con plantas en cuatro continentes, ya que el mercado financiero juzga a las transnacionales sin referencia al riesgo del país de origen sino sobre la base de sus activos globales ${ }^{82}$. De esta forma, su estrategia ha sido invertir en adquisiciones de empresas las ganancias generadas por una nueva demanda internacional de aceros planos y largos (sobretodo del mercado chino) y de tubos sin costura (de las compañías petroleras), además de adquirir deuda en una coyuntura financiera favorable para su crédito ${ }^{83}$. En 2007 Techint anunció la compra de Industrias Monterrey, S.A. (IMSA), que se sumó a Ternium y se fusionó con Hylsamex en una sola organización, que representa $40 \%$ del mercado mexicano ${ }^{84}$.

$\mathrm{Al}$ anunciarse la compra de Hylsamex, los analistas opinaban que la adquisición de una empresa concentrada en la producción de acero para la industria automotriz norteamericana reducía su riesgo en Venezuela donde Ternium enfrentaba presiones del gobierno por Sidor. Estas presiones se concretaron en abril de 2008, cuando el gobierno venezolano re-estatizó Sidor, después de un conflicto entre empresa y trabajadores por la renegociación de su contrato colectivo. La decisión venezolana no fue inesperada para Techint porque las compras de Hylsamex e IMSA, que exigieron un alto desembolso de recursos y el endeudamiento del grupo,

79 Según su vicepresidente ejecutivo, Daniel Novegil, “Siderar apuesta..." (2003); Boletín de Prensa, Hylsamex, 25/11/2005, www.hylsamex.com.mx. En 2/03/2006 Novegil declaró a El Universal (Caracas) que Ternium es "una compañía con base industrial americana, porque... en la región existen ventajas comparativas para producir acero, que no existen en otras".

"Ternium increases..." (2006).

"Creó..." (2005); Boletín de Prensa, 22/08/2005, www.hylsamex.com.mx

"Redefining..." (2006).

Stok (2005), pp. 32-33.

Sobre IMSA, Cerutti (2000), pp. 225-240; “Ternium says..." (2007); sobre su venta, El Financiero (México) www.elfinanciero.com.mx. En 2008, Techint vendió activos de Hylsamex e IMSA en EE.UU., considerados no estratégicos, y prepagó parte de su deuda, "Ternium completes..." (2008). 
parecen indicar un movimiento de activos desde un mercado políticamente inseguro (Venezuela) a otro más seguro (México) y con acceso al mercado estadouniden$\mathrm{se}^{85}$. Esto explicaría por qué las acciones de Ternium aumentaron de precio después de la re-estatización de Sidor ${ }^{86}$.

Entre 2006 y 2007, Techint compró también Maverick y Hydril en EE.UU., con plantas en Canadá y Colombia, para agrupar empresas productoras de tubos sin y con costura, que ofrecen servicios integrales, en siete países. Esta estrategia de expansión dentro del mismo sector (consolidación) busca eliminar la atomización relativa en el sector siderúrgico mundial, frente a proveedores de insumos -industria productora de mineral de hierro- y clientes - industria transformadora- fuertemente concentrados ${ }^{87}$. Esto permite que productores eficientes desplacen a los ineficientes, logrando un mayor control sobre los precios y evitando crisis por sobreoferta $^{88}$.

La estrategia de Techint de organizar sus empresas en compañías transnacionales permitió centralizar actividades como compras y programas de investigación y desarrollo, rotar personal calificado, establecer acuerdos comerciales y tecnológicos, formar recursos humanos y ampliar el reclutamiento de personal ${ }^{89}$. Por ejemplo, producto de las tareas de investigación y desarrollo de Tenaris en Argentina, México e Italia son: la Tenaris Blue, una tuerca que une tubos de gasoductos sin materia grasa y con menor contaminación ambiental; un tubo capaz de soportar temperaturas de 698 grados Fahrenheit, para extraer petróleos pesados, y una tubería para producción de gas y petróleo offshore a mayores profundidades ${ }^{90}$.

Entre los ochenta y noventa, Techint se constituyó como holding, diferenciando sus funciones productivas y corporativas ${ }^{91}$, pero mantuvo la estructura de empresa familiar, con una división entre los tres hermanos Rocca (Agostino, Paolo y Gian Felice), al retirarse su padre ${ }^{92}$. En 2001 pasó a llamarse Organización Techint y se organizó en función de áreas de negocios globales, con Paolo al frente de la siderúrgica y sus hermanos dividiéndose el resto ${ }^{93}$. Meses después, la muerte de Agostino en un accidente aéreo colocó a Paolo a la cabeza del grupo. En ese momento se consolidó el control de Techint sobre Tenaris, mediante el canje de acciones de Siderca, Dalmine y Tamsa por otras de Tenaris. En el 2002 estas compañías salieron de

\footnotetext{
“Ternium to take..." (2007). En mayo de 2007, el gobierno venezolano había amenazado con re-estatizarla, "Sidor expects..." (2007) y el gobierno argentino medió para alcanzar un acuerdo, Olivera (2005 a y b).

"Para reemplazar..." (2008).

"El desafío..." (2002), pp. 39-41.

Paolo Rocca en “El desafío..." (2002), p. 40; “Creó..." (2005).

Kosacoff (1999), pp. 125-126.

“Techint busca..." (2004).

Bisang (1998), p. 137.

Kosacoff (1999), p. 137.

Naishtat (2001).
} 
sus respectivas bolsas y Tenaris inauguró su participación en la de Nueva York, como después lo haría Ternium ${ }^{94}$.

En sus relaciones con el entorno político, en los noventa, Techint apoyó políticas para favorecer la reindustrialización exportadora, afectada por el ingreso de capital extranjero en los procesos de privatización y por la compra de grandes empresas y grupos $^{95}$. Su experiencia durante el gobierno militar, cuando la política económica benefició a los sectores financieros y perjudicó a los industriales - entre 1975 y 1982 la participación de la industria en el PIB argentino cayó de 28 a 22\% - explica su participación activa en distintas asociaciones empresariales, luego del retorno de la democracia $^{96}$. Para fines de los ochenta, representantes del grupo tenían posiciones destacadas en la Cámara de la Construcción, la asociación de exportadores, el Centro de Industriales Siderúrgicos, la Unión Industrial Argentina (UIA) y el Consejo Empresarial Argentino ${ }^{97}$. La política económica de esos años ni favoreció ni perjudicó a Techint, pero, según Nudler, como el grupo estaba enfocado al acero y al petróleo, se sintió cómodo dentro de un modelo que acentuaba la especialización en commodities $^{98}$.

Como la privatización en Argentina se llevó a cabo en un contexto de apertura comercial, que permitía el ingreso de aceros brasileños y de los provenientes de Asia y el Este de Europa, las empresas siderúrgicas no lograron implantar un verdadero oligopolio. Esto explica por qué Techint se asocia a corrientes empresariales que defienden la producción argentina. En los últimos años, Paolo Rocca es considerado el líder del grupo "Industriales" de la UIA, que respaldó a los gobiernos de Eduardo Duhalde y Néstor Kirchner ${ }^{99}$. La actividad política de Paolo contrasta con la de su padre y antecesor al frente de Techint, quien declaraba su disgusto con la participación de los empresarios en política ${ }^{100}$.

\section{Análisis comparado de sus trayectorias estratégicas}

Al resumir la trayectoria estratégica de Hylsamex, encontramos que su creación respondió a la necesidad de sustituir un producto importado cuyo acceso resultaba limitado para México durante la segunda guerra mundial. En los cincuenta, se privi-

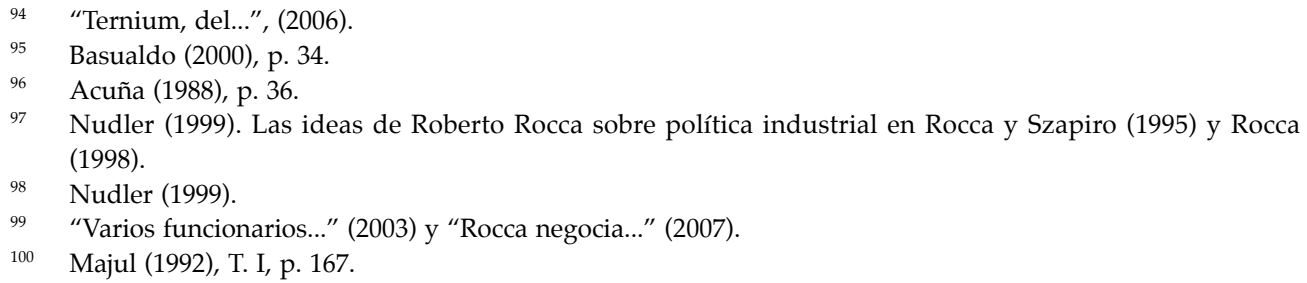


legió la innovación tecnológica y la exportación de tecnología, buscando reducir el costo de producción. Para los sesenta, Alfa integró paulatinamente otras etapas productivas (minas, etc.). En los setenta, se endeudó en el exterior para comprar empresas subsidiarias y diversificarse hacia otras actividades. Su primer momento de inflexión se dio con la crisis de la deuda externa que casi precipitó la quiebra del grupo, forzándole a recurrir al Estado para evitarla. En ese momento, las estrategias fueron una nueva concentración en sectores claves como acero, venta de acciones y énfasis en la exportación, apoyada en la devaluación del peso y los bajos salarios. Cuando la familia Garza Sada recuperó el control accionario (1988), se pasó a realizar alianzas estratégicas con empresas internacionales, principalmente estadounidenses, e inversiones en servicios y en productos siderúrgicos con mayor valor agregado. Al no poder adquirir ninguna de las siderúrgicas estatales que se privatizaron, se invirtió en la privatización en el exterior contrayendo nuevas deudas (segundo momento de inflexión). En el 2000, el cierre de minas y algunas plantas debido al nivel de endeudamiento, al alza del precio de los insumos y a la coyuntura negativa para las exportaciones de acero mexicano marcó un tercer momento. La estrategia de Alfa se concentró en empresas cuyos productos no estuvieran sujetos a movimientos cíclicos y en sanear las finanzas de Hylsamex para venderla a Techint en 2005.

En la Sección II observamos que la creación de Siderca (1954) se debió a la demanda de tubos de acero sin costura para gasoductos y oleoductos, en un mercado en el cual no había otros productores de tubos de ese tipo. En los sesenta, la creación de Propulsora Siderúrgica fue parte de una estrategia de ampliación que enfrentó la oposición del gobierno, pero que, en los noventa, permitió establecer Siderar. En su primera etapa, Siderca reinvirtió utilidades para poder mantenerse y crecer, además de adquirir tecnología. El primer momento de inflexión de Siderca se dio en los setenta, cuando el boom en los precios internacionales del petróleo impulsó sus exportaciones. En los noventa, tanto Siderar como Siderca adquirieron y controlaron otras empresas latinoamericanas (Sidor, Tamsa) y no latinoamericanas (Dalmine, etc.). Esto fue acompañado por la búsqueda de una mayor diversificación mediante la privatización de distintos servicios públicos, que duró poco tiempo (segundo momento). La internacionalización de Siderca y Siderar llevó en la década del 2000 a crear dos empresas globales, Ternium y Tenaris, con lo cual Techint pasó a una estrategia que enfatiza la producción de acero y el servicio al cliente. Esto permitió aislar a sus empresas de las incertidumbres del mercado argentino, después del default de 2001, y simplificar funciones y reducir costos e inversiones en tecnología. Este puede considerarse otro momento de inflexión y la compra de Hylsamex por Techint en 2005 fue parte del mismo.

Pasando del análisis comparativo longitudinal al transversal, a continuación se compara, en primer lugar, el origen de las empresas y sus razones para ingresar al sector siderúrgico; en segundo lugar, sus estrategias internas (inversión en innova- 
ción y desarrollo tecnológico, conformación como holding, etc.) y, finalmente, sus estrategias externas para relacionarse con el mercado o para vincularse con el ámbito político.

En cuanto a origen de las empresas, Hylsa fue creada después de una larga asociación entre empresas del mismo grupo familiar. Dalmine SAFTA fue la primera empresa industrial de un grupo fundado hacía poco tiempo, sin antecedentes fabriles pero con buen respaldo financiero y cuyo líder tenía experiencia en dirección de siderúrgicas ${ }^{101}$. Existieron diferencias en el contexto en que se insertaron porque, aunque se beneficiaron de la política sustitutiva de importaciones, la industria del acero en Argentina se asociaba a un proyecto militar, lo que determinó que se le impusiera condiciones que limitaban la participación del capital privado ${ }^{102}$.

Las dos empresas importaron maquinaria y tecnología y aprovecharon coyunturas domésticas favorables a la industrialización para expandirse. En su financiamiento inicial, Hylsa fue apoyada por créditos estatales de México y EE.UU., mientras Techint utilizó fondos propios, crédito privado y otros del Banco Industrial. El desarrollo de la siderurgia, impulsado por la guerra, la reconstrucción europea y el surgimiento de Japón, hizo que, para fines de los cincuenta, fuera necesario modernizar el equipamiento de Hylsa, que realizó inversiones en innovación y desarrollo que culminaron en la tecnología Hyl. Así el atraso tecnológico determinó una estrategia que facilitó su primera expansión en el exterior, mediante la venta de servicios tecnológicos y plantas Hyl. La innovación tecnológica no estuvo ausente en Dalmine SAFTA pero se manifestó en la adquisición de tecnología de punta.

La internacionalización de estas empresas fue temprana y se caracterizó por una primera fase de exportación de servicios - tecnología, en Hylsa, y asesoría técnica y proyectos, en Techint. Siderca exportaba tubos para la industria petrolera antes de la crisis de la deuda, que llevó a Hylsa a orientarse hacia su exportación. Desde entonces, su competencia ha sido multidoméstica —utilizar las ventajas en México para exportar a otros países-, mientras la de Techint es mundial, dispersar actividades mediante inversiones directas ${ }^{103}$. Otra diferencia en las estrategias de ambos grupos en relación con sus empresas siderúrgicas es que Alfa invirtió en minas de hierro desde los cincuenta, mientras que Techint no tuvo acceso directo a mineral de hierro hasta adquirir Somisa en los noventa. En cambio, invirtió en procesos para bajar el consumo de mineral de hierro con el reciclaje interno de cada planta (sinterización) ${ }^{104}$.

\footnotetext{
101 Según Roberto Rocca, Techint tuvo acceso a un fondo de inversión en Italia, Majul, (1992), T. I, p. 156, canalizado por Santa María S.A., empresa financiera fundada en 1948, Castro (2003), p. 140.

102 Schvarzer (1996), pp. 206-209.

103 Porter (1991), pp. 88-89, 92-93.

104 Declaraciones de Raúl Ametrano, Jefe Materias Primas y Sinter, Siderar, en “Situación de..." (2001), pp. 30-31.
} 
Techint se organizó como holding después que Alfa, antes VISA. Sin embargo, desde el comienzo Techint no estuvo conformado sólo por la familia Rocca, ya que se observa la presencia de apellidos claves en puestos de responsabilidad en la empresa. Ambos grupos invirtieron en formar profesionales de calidad en ingeniería y administración de empresas - Alfa mediante la fundación del ITESM y Techint, con el desarrollo de los profesionales para establecer una planta siderúrgica integrada.

Techint sufrió menos con la crisis de la deuda en los ochenta porque su nivel de endeudamiento no era tan alto como el de Alfa ni estaba sobreexpuesto por inversiones en distintos sectores. Hylsa sobrellevó la crisis y ayudó a la recuperación del Grupo Alfa con su internacionalización, pero éste debió recibir ayuda financiera del Estado mexicano. Techint se benefició de las continuas devaluaciones monetarias en Argentina, que facilitaron el pago de sus deudas externas, y de no ser propietario de bancos, porque evitó las quiebras que se produjeron en el sector bancario. Lo anterior se relaciona con el distinto contexto económico de México y Argentina en los setenta. México, exportador petrolero, vivió una expansión económica impulsada por su casi ilimitado crédito externo, que produjo un endeudamiento público y privado alto, imposible de mantener luego de la caída de los precios petroleros y del alza de las tasas de interés internacionales. Mientras tanto, la inestabilidad política de Argentina en los setenta hizo que su endeudamiento fuera menor en términos relativos, pero impagable para la economía argentina.

La privatización del sector siderúrgico mexicano fue negativa para Alfa, que no pudo comprar ninguna empresa estatal grande, y alteró la estructura del mercado doméstico aumentando la competencia, con lo cual Hylsamex perdió poder. Esto la llevó a invertir en la privatización de Sidor y a vincularse con el mercado del TLCAN a través de la industria automotriz. Por su parte, Techint en los noventa adquirió empresas estatales en Argentina, México y Venezuela y las integró en un esquema regional de producción.

Con respecto a las relaciones con el poder político, ambos grupos tuvieron relaciones ambiguas con él. Eugenio Garza Sada y Agostino Rocca no mantuvieron relaciones cercanas con los gobiernos de México y Argentina pero se beneficiaron de sus políticas industriales ${ }^{105}$. El mayor apoyo gubernamental lo obtuvo Alfa al producirse la crisis de la deuda, cuando el gobierno mexicano salvó al grupo de su quiebra. En Techint hubo reticencia a acercarse al poder político y su actividad se dio a través de asociaciones empresariales. Desde 2001, asumió un perfil más activo asociándose con sectores afines al gobierno argentino.

En el Cuadro 1 se sintetizan las estrategias de ambas empresas/grupos junto con el contexto siderúrgico global.

105 La opinión de Rocca acerca del peronismo en Lussana (1999) y sobre otras administraciones, en Schvarzer (1996), pp. 245-246. 


\section{CUADRO 1}

CONTEXTO DEL SECTOR SIDERÚRGICO Y ESTRATEGIAS EMPRESARIALES (1950-2005)

\begin{tabular}{|c|c|c|c|}
\hline Años & $\begin{array}{l}\text { Contexto } \\
\text { siderúrgico }\end{array}$ & HYLSA/ALFA & $\begin{array}{c}\text { SIDERCA-SIDERAR/ } \\
\text { TECHINT }\end{array}$ \\
\hline $\begin{array}{l}\text { Década de } \\
\text { los } 50\end{array}$ & $\begin{array}{l}\text { Reconstrucción europea/ } \\
\text { industrialización de Japón/ } \\
\text { problemas de suministro }\end{array}$ & $\begin{array}{l}\text { Aprovecha políticas públicas/ } \\
\text { desarrolla tecnologías }\end{array}$ & $\begin{array}{l}\text { Aprovecha políticas públi- } \\
\text { cas/exporta servicios/rein- } \\
\text { vierte utilidades }\end{array}$ \\
\hline $\begin{array}{l}\text { Década de } \\
\text { los } 60\end{array}$ & $\begin{array}{l}\text { Surgen nuevos producto- } \\
\text { res de acero en países en } \\
\text { desarrollo }\end{array}$ & $\begin{array}{l}\text { Exporta tecnología/se expande } \\
\text { en México }\end{array}$ & $\begin{array}{l}\text { Comienzan exportaciones/ } \\
\text { invierte en tecnología de } \\
\text { punta }\end{array}$ \\
\hline $\begin{array}{l}\text { Década de } \\
\text { los } 70\end{array}$ & $\begin{array}{l}\text { Cambio tecnológico/ altos } \\
\text { precios del petróleo/ caída } \\
\text { de demanda de aceros } \\
\text { planos }\end{array}$ & $\begin{array}{l}\text { Rápido crecimiento/ endeuda- } \\
\text { miento por reconversión tecno- } \\
\text { lógica y adquisiciones/diversifi- } \\
\text { cación/organización como } \\
\text { holding }\end{array}$ & $\begin{array}{l}\text { Aumenta demanda de tu- } \\
\text { bos sin costura para indus- } \\
\text { tria petrolera }\end{array}$ \\
\hline $\begin{array}{l}\text { Década de } \\
\text { los } 80\end{array}$ & $\begin{array}{l}\text { Sobreproducción/nuevos } \\
\text { productores en mercado } \\
\text { mundial/prácticas deslea- } \\
\text { les de comercio }\end{array}$ & $\begin{array}{l}\text { Crisis de la deuda y apertura } \\
\text { comercial fuerzan internacio- } \\
\text { nalización (exportaciones)/ven- } \\
\text { tas de activos/reducción perso- } \\
\text { nal corporativo }\end{array}$ & $\begin{array}{l}\text { Primeras oficinas comer- } \\
\text { ciales en EE.UU. y China/ } \\
\text { desarrollo de estándares } \\
\text { internacionales }\end{array}$ \\
\hline $\begin{array}{l}\text { Década de } \\
\text { los } 90\end{array}$ & $\begin{array}{l}\text { Especialización productiva } \\
\text { entre desarrollados y en } \\
\text { desarrollo/ privatización } \\
\text { de siderurgias estatales } \\
\text { latinoamericanas }\end{array}$ & $\begin{array}{l}\text { Reorganización corporativa/in- } \\
\text { versión en tecnología actuali- } \\
\text { zada/asociaciones estratégicas } \\
\text { con empresas extranjeras/in- } \\
\text { versión en Sidor (Venezuela) }\end{array}$ & $\begin{array}{l}\text { Privatización de Somisa, } \\
\text { Sidor y control de Dálmine } \\
\text { y Tamsa/mayor integración/ } \\
\text { holding/diversificación tem- } \\
\text { poral }\end{array}$ \\
\hline $\begin{array}{l}\text { Década del } \\
2000\end{array}$ & $\begin{array}{l}\text { 1. }^{a} \text { etapa: mercado depri- } \\
\text { mido/subsidios siderúrgi- } \\
\text { cos/aranceles altos de } \\
\text { EE.UU. al acero*/consoli- } \\
\text { dación }\end{array}$ & $\begin{array}{l}\text { Peso de deudas contraídas en } \\
\text { los } 90 / \text { cierre de plantas por } \\
\text { alza de precios del hierro y del } \\
\text { gas en mercado doméstico/re- } \\
\text { ducción de costos }\end{array}$ & $\begin{array}{l}\text { Organización en transna- } \\
\text { cionales (Tenaris y Ter- } \\
\text { nium)/mayor poder en mer- } \\
\text { cado global y regional/ } \\
\text { adquisiciones y control ac- } \\
\text { cionario }\end{array}$ \\
\hline 2005 & $\begin{array}{l}\text { 2. }{ }^{a} \text { etapa: auge de deman- } \\
\text { da (China) y créditos fáci- } \\
\text { les/nuevo boom petrolero/ } \\
\text { consolidación }\end{array}$ & $\begin{array}{l}\text { Venta de Hylsamex para pasar } \\
\text { a rubros con mayor valor agre- } \\
\text { gado }\end{array}$ & $\begin{array}{l}\text { Adquisición de Hylsamex } \\
\text { para concentrarse en ace- } \\
\text { ro }\end{array}$ \\
\hline
\end{tabular}

\footnotetext{
* Se aplicaron hasta diciembre 2003 a empresas de países cuyas importaciones excedían el 3\% de las importaciones estadounidenses. México quedó exento por el TLCAN y Argentina, porque sus importaciones representaban menos del 3\%, Correio Sindical Mercosul (2002), pp. 10-11. Los países que no podían exportar a EE.UU. abarrotaron el mercado mundial de acero, haciendo bajar los precios, "Bush levantó..." (2003), p. 4.
} 
En resumen, hasta los setenta los dos grupos se beneficiaron de políticas que protegían la producción industrial, pero Techint mostró mayor preocupación por reinvertir utilidades dados los obstáculos que enfrentaba. Esto lo llevó a orientar a Dalmine-Siderca, y luego a Propulsora, hacia las exportaciones. Su especialización en tubos para la industria petrolera produjo beneficios durante el boom de los precios internacionales del petróleo. Mientras en esa década Alfa se endeudó para adquirir tecnología importada y realizar adquisiciones para Hylsa en México. Ambas estrategias se pusieron a prueba al producirse la crisis de la deuda porque Alfa se salvó apenas de la quiebra y Techint se expandió hacia mercados nuevos.

En los noventa, Techint creció más en el exterior que en Argentina y su diversificación duró menos tiempo. Alfa se diversificó pero no consiguió privatizar ninguna estatal grande e invirtió menos en acero en el exterior. Cuando en el 2000 el sector siderúrgico cayó en una etapa de sobreproducción y precios bajos, Alfa decidió abandonar el acero por otras producciones con mayor valor agregado. Techint estaba en mejores condiciones para seguir invirtiendo en la fase de baja del ciclo del acero - cuando la mayor parte de las empresas no lo hacen-y siguió una estrategia de mayor concentración, mediante la creación de compañías transnacionales.

La incidencia en las estrategias adoptadas de los contextos en que se desenvuelven las empresas puede observarse desde dos ángulos. El primero es que en México se ha producido desde 1995 un estancamiento en la exportación de commodities y un aumento relativo de las exportaciones de productos más industrializados - tendencia que se refleja en la venta de Hylsamex para concentrarse en rubros más elaborados. El comportamiento de Techint sigue las tendencias del mercado argentino, que se ha vuelto a especializar en la exportación de commodities, y se refleja en el fin de su diversificación para concentrarse en la producción y exportación de acero. El otro ángulo es el de la posición de cada empresa/grupo en su contexto sectorial porque, mientras las empresas de Techint son líderes del sector siderúrgico argentino, en México, Hylsamex perdió poder relativo desde la privatización del acero, lo cual repercutió en la posición relativa de Alfa. Esto corrobora que las estrategias de las empresas tienen en cuenta no sólo la estructura de su sector sino también su posicionamiento en él ${ }^{106}$.

Si las estrategias de los grupos reflejan las tendencias de su contexto nacional y sectorial, también tienen importancia sus propias características porque, en el proceso de definir acciones a futuro, influye su historia previa. Parte de la incertidumbre que enfrentan las transnacionales latinoamericanas no puede mitigarse con la acción estatal porque se asocia al mercado global y las empresas la enfrentan con los recursos del saber productivo y gerencial acumulado históricamente. De este modo,

106 Porter (1991), p. 63. 
su trayectoria estratégica determina futuros cursos de acción, sobre la base de lo que los agentes consideran probable y de lo que se creen capaces de hacer ${ }^{107}$.

Esto se observa, en especial, en las estrategias adoptadas en sus momentos de inflexión. En Hylsamex / Alfa fue determinante su experiencia negativa durante la crisis de la deuda externa (primer momento de inflexión), a la cual se agregó su incapacidad de privatizar empresas estatales grandes en los noventa y su endeudamiento en esa década (segundo momento). El alto nivel del mismo determinó que, durante la fase de baja del acero después del 2000, se planteara su venta, pues mantenerla obligaba a desviar ganancias de otras empresas hacia ella, cuando existían opciones más rentables. En este tercer momento de inflexión, adquirió importancia su percepción de no ser ya el principal grupo económico ni la principal empresa siderúrgica mexicana.

En la trayectoria estratégica de Techint hay también tres momentos de inflexión —en los setenta, cuando la especialización en tubos para la industria petrolera aumentó su demanda en el mercado internacional y ayudó a que Siderca sobrellevara la crisis de la deuda y se expandiera hacia nuevos mercados. El segundo fue en los noventa, cuando Techint privatizó Somisa y Sidor y controló Dalmine (Italia) y Tamsa, convirtiéndose en jugador regional y global, a la vez que intentaba diversificarse. Su estrategia desde el 2000, incluyendo la adquisición de Hylsamex, consiste en reinvertir utilidades de fases expansivas en la compra de empresas siderúrgicas que se articulan en empresas globales (tercer momento). En resumen, el acero es para Techint una "estrella ascendente" y, para Alfa, una "estrella declinante", como resultado de sus respectivas trayectorias estratégicas y de sus contextos sectoriales y nacionales.

\section{Conclusiones}

El contexto de las empresas es una dimensión a la cual algunos consideran que Chandler no presta atención al estudiar las estrategias empresariales ${ }^{108}$. En realidad, este factor está incorporado en su modelo mediante las presiones externas que producen los cambios de estrategia, pero su limitación es que no elabora las causas que llevan a distintas empresas a responder de forma diferente a presiones similares. Aquí es donde alcanzan relevancia las trayectorias estratégicas previas de las empresas.

Las respuestas divergentes a presiones similares surgen a partir de las visiones de sí mismas que las empresas construyen en su desarrollo histórico. Si en Alfa pesó el antecedente negativo de la crisis de la deuda, que amenazó el control familiar del grupo, en Techint lo hizo el hecho de que los momentos negativos en su historia

107 Dal Bó y Kosacoff (1998), pp. 136-142.

108 Koll (2000), p. 1; Williamson (2005), p. 27. 
fueron de corta duración. Existió además una percepción diferente de la situación de la empresa/grupo - la pérdida de poder relativo de Alfa significaba menor posibilidad de apoyo estatal para resolver potenciales problemas; mientras Techint se encontraba en ascenso en Argentina y en el ámbito internacional. Otra característica de su desarrollo interno que influye en sus estrategias es que Alfa está diversificado y tiene opciones productivas que ofrecen mayores márgenes de ganancia que el acero ${ }^{109}$; Techint está más concentrado en acero, tiene mayor poder global y busca aprovechar la crisis para incrementarlo.

Encontramos que, en general, los cambios en estrategia se dieron con cambios en estructura, pero la diferencia con el modelo chandleriano es que los cuadros gerenciales no han desplazado a las familias de la toma de decisiones estratégicas. Declaraciones de Dionisio Garza Medina y Paolo Rocca, presidentes de Alfa y Techint, respectivamente, muestran su rol activo en las estrategias adoptadas recientemente. Estas pueden haberse enriquecido con la participación de gerentes, pero el impacto de las estrategias sobre la estructura de la empresa no ha producido cambios en su dirección.

Otra diferencia es que la dirección familiar no resultó negativa para el éxito de las empresas/grupo. Más bien parece una constante del panorama de las empresas latinoamericanas exitosas, porque 210 de las 500 mayores en 2007 estaban bajo control familiar. Algunos sugieren que la toma de decisiones por uno o pocos accionistas agiliza el proceso y facilita su acercamiento al Estado ${ }^{110} \mathrm{y}$ otros, que estas empresas enfrentan menos presiones de sus accionistas y pueden planear estrategias de largo plazo ${ }^{111}$. Como en los países asiáticos también existe control familiar sobre empresas transnacionales exitosas, ello sugiere que el modelo chandleriano responde a condiciones de la cultura organizacional estadounidense a fines del siglo XIX, que no se dan en otros contextos ${ }^{112}$.

Finalmente, sin pretensión de revisar la literatura sobre empresas latinoamericanas debido a la amplitud y complejidad del tema, nuestros estudios de caso siguen parámetros empleados por Barragán y Cerutti al estudiar el paso de Cemex a empresa global ${ }^{113}$. Además, intenta, por una parte, complementar objeciones hechas a la aplicación del modelo chandleriano en publicaciones mexicanas y brasileñas ${ }^{114}, y$, por otra, contribuir a superar una limitación general de la literatura sobre empresas - los numerosos estudios de casos que no se articulan en estudios comparativos ${ }^{115}$.

\footnotetext{
109 Cerutti (2000).

110 Becerra y Nieponice (2008).

111 Thomson (2008).

112 Koike (1993).

113 Barragán y Cerutti (2003).

114 Barbero (2008), pp. 566-567.

115 Barbero (2008), p. 574.
} 
Un antecedente fundamental para nuestro planteamiento proviene de la teoría económica, combina los enfoques institucionalista y evolucionista y fue elaborado por Dal Bo y Kosacoff, quienes consideran a las empresas como organizaciones que evolucionan a partir de una red de interacciones repetidas. Estas determinan un proceso de aprendizaje que influye en la selección de estrategias por parte de las empresas. Creemos que quizás sea hora de poner en perspectiva éstos y otros elementos, encontrados en la literatura sobre empresas y que, a veces, parecen pasar desapercibidos, para combinarlos en estudios de mayor alcance teórico.

\section{Revistas y/o periódicos}

\section{Acero Latinoamericano}

— "Situación de materias primas ferrosas" (2001): Acero Latinoamericano, 465 (marzo-abril), pp. 24-33.

- "El desafío es ser protagonista pese a la adversidad" (2002): Acero Latinoamericano, n. ${ }^{\circ} 470$ (enero-febrero), pp. 39-41.

— "Siderurgia en América Latina y sus perspectivas en el 2003" (2003): Acero Latinoamericano, 478 (mayo-junio), pp. 8-16.

\section{Boston.com}

- "Ternium increases its stake in Siderar" (2006): The Boston Globe, December 29, www.boston.com/business/articles/2006/12/29.

\section{Clarín.com}

- "Ternium, del Grupo Techint, debutó en Wall Street con una subida de 15\%" (2006): www.clarín.com/diario/, 2/02/2006.

- NAISHTAT, Silvia (2001): “Techint encara una fuerte reorganización internacional" Clarín, 5/04/2001.

\section{Investors.com}

— "Ternium completes sale of non-core U.S. assets" (2008): February 1, www. investors.com/breakingnews.

\section{Lanación.com.ar}

— “Tenaris invertirá 32 millones de dólares" (2003): www.lanación.com.ar 3/06/2003. 
- "El grupo económico más fuerte del país" (2003): www.lanacion.com.ar, $11 / 06 / 2003$.

- "Siderar apuesta a la recuperación y busca el liderazgo americano" (2003): La Nación (Buenos Aires), 8/08/2003, p. 8.

- "Varios funcionarios cantaron el presente en un encuentro industrial" (2003). www.lanación.com.ar, 9/08/2003.

- “Tenaris abrirá una planta" (2003): www.lanacion.com.ar, 2/12/2003.

- "Bush levantó trabas al ingreso de acero" (2003): www.lanacion.com.ar, $5 / 12 / 2003$, p. 4.

- "Techint busca mercados con nuevos productos" (2004): www.lanacion.com.ar $15 / 03 / 2004$.

- "Creó el Grupo Techint una gigantesca acerera" (2005): www.lanacion.com.ar, $23 / 08 / 2005$

- OLIVERA, Francisco (2005a): “Techint aceptó las exigencias del gobierno venezolano", www.lanacion.com.ar, 1/11/2005.

- OLIVERA, Francisco (2005b): "Techint pagará a Venezuela $66 \%$ más", www. lanacion.com.ar, 7/11/2005.

- "Rocca negocia con Chávez en Caracas el futuro de Sidor" (2007): www.lanacion.com.ar 15/05/2007.

- "Para reemplazar a Sidor, Techint invertiría en una planta en Brasil" (2008): www.lanacion.com.ar, 6/06/2008.

\section{LatinFinance.com}

- "Redefining their role" (2006): www.LatinFinance.com, X www.institutionalinvestor.com/Article, 25/01/2006.

\section{Manattjones.com}

- "Steelmaker Hylsamex halts bankruptcy" (2004): Reforma, November 29, www. manattjones.com/newsletters/newsbrief/20041209.html

\section{Reuters.com}

- “Ternium to take control of Mexico's Imsa" (2007): April 30, www.reuters.com/ article.

- "Sidor expects to avoid Venezuela takeover-report" (2007): www.uk.reuters. com/article, May 16, 2007.

- “Ternium says it will merge Mexico's Hylsamex and Imsa" (2007): August 3, www.reuters.com/article/marketsNews/ 
Tenaris.com

- "Tenaris. El rebranding del área tubos de la Organización Techint" (2001): Boletín Informativo Techint, 308 (octubre-diciembre), pp. 2-19.

— "Tenaris Annual Report 2007" (2008): www.tenaris.com.

Ternium.com

— “Ternium Annual Report 2005 (2006): www.ternium.com.

— “Ternium Annual Report 2006 (2007): www.ternium.com.

\section{Bibliografía}

ACUÑA, Carlos (1988): “Empresarios y política”, Boletín Informativo Techint 255, noviembre-diciembre.

ALFA (2001): "Redefining our business portfolio" ALFA 2000 Annual Report (March 5), www.alfa.com.mx/AnnualReport.

ALTENBURG, Tilman y MESSNER, Dick (2002): “Introducción” en ALTENBURG, T. y MESSNER, D. (eds.), América Latina competitiva, Caracas, Nueva Sociedad, pp. 7-13.

ASPIAZU, Daniel y BASUALDO, Eduardo (1993): La siderurgia argentina en el contexto del ajuste, las privatizaciones y el Mercosur, Buenos Aires, Instituto de Estudios sobre Estado y Participación.

ASPIAZU, Daniel y VISPO, Adolfo (1994): “Algunas enseñanzas de las privatizaciones en Argentina", Revista de la CEPAL 54 (diciembre), pp. 31-54.

BARBERO, María Inés (2008): “Business History in Latin America: A Historiographical Perspective", Business History Review, 82 (Autumn), pp. 555-575.

BARRAGÁN, Juan Ignacio y CERUTTI, Mario (2003): “Cemex: del mercado interno a la empresa global", Anais do V Congresso de História Econômica e $6^{a}$ Conferencia Internacional de Historia de Empresas, Sao Paulo, Brasil, www.abphe.org.br/congresso2003.

BASUALDO, Eduardo (2000): Concentración y centralización del capital en la Argentina durante la década del noventa, Bernal, Universidad de Quilmes.

BASUALDO, Eduardo y ASPIAZU, Daniel (1989): Cara y contracara de los grupos económicos, Buenos Aires, Cántaro.

BECERRA, Jorge y NIEPONICE, Gustavo (2008): “El desafío de las desafiantes", América Economía", 356 (30/03/2008).

BISANG, Roberto (1998): "La estructura y dinámica de los conglomerados económicos en Argentina" en PERES, W. (ed.), Grandes empresas y grupos industriales latinoamericanos, México, Siglo XXI, pp. 81-150. 
BISANG, Roberto y CHIDIAK, Mariana (1995): “Apertura económica, reestructuración productiva y medio ambiente", Buenos Aires, IDRC.

BISANG, Roberto y KOSACOFF, Bernardo (1992): “Exportaciones industriales en una economía en transformación”, Boletín Informativo Techint 271 (julio-setiembre), pp. 61-100.

CASTRO, Claudio (2003): “De la industrialización tardía europea a la sustitución de importaciones latinoamericana", Revista Ciclos, Año XIII, Vol. XIII, n. ${ }^{\circ} 25-26$ $\left(1^{\mathrm{er}} / 2^{\circ}\right.$ semestre), pp. 119-144.

-(2005): "Política industrial y empresa" Anuario del Centro de Estudios Históricos Profesor Carlos Segreti, Córdoba, n. ${ }^{\circ}$ 5, Año 5.

-(2007): “Un nuevo actor siderúrgico en la Argentina de posguerra: el Grupo Techint" en ROUGIER, M. (ed.), Política de promoción y estrategias empresariales en la industria argentina, 1950-1980, Buenos Aires, Ediciones Cooperativas, pp. 83-107.

CERUTTI, Mario (2000): Propietarios, empresarios y empresas en el Norte de México, México, Siglo XXI.

CHANDLER, Alfred (1962): "Introduction to Strategy and Structure" en McCRAW, T. (ed.), The Essential Alfred Chandler, Boston, Harvard Business School Press, pp. 161-178.

-(1990): Scale and Scope, Cambridge \& London, The Belknap Press.

CHUDNOVSKY, Daniel; KOSACOFF, Bernardo y LÓPEZ, Andrés (1999): "Presentación" en CHUDNOVSKY, D., KOSACOFF, B. y LÓPEZ, A. (eds.), Las multinacionales latinoamericanas, México, FCE, pp. 7-10.

CORREIO SINDICAL MERCOSUL (2002), n. ${ }^{\circ} 103$ (9-16/03/2002).

DAL BÓ, Ernesto y KOSACOFF, Bernardo (1998): “Líneas conceptuales ante evidencias microeconómicas de cambio estructural" en KOSACOFF, B. (ed.), Estrategias empresariales en tiempos de cambio, Bernal, Universidad de Quilmes, pp. 123-153.

DÁVILA, Anabella (1997): “Elementos para el diseño de una empresa diversificada ante una crisis económica" en GERTNER, D., BOCATER, P. F. y LEAL, R. P. (eds.), Proceedings of the Business Association for Latin American Studies, Rio de Janeiro, Brazil.

-(2000): "Restructuring for Divestiture", Annual Meeting of the Academy of Management, Toronto, Canadá.

FLORES, Oscar (2000): Monterrey Industrial, 1890-2000, Monterrey, Universidad de Monterrey.

FLORES, Oscar y DAVILA, Anabella (2001): "Reestructuración de las empresas siderúrgicas en Monterrey ante la apertura comercial, 1970-1998" en BEHAR, J.; GIACALONE, Rita y MELLADO, N. (eds.), Integración regional de América Latina. Procesos y actores, Estocolmo, Universidad de Estocolmo, pp. 86-112. 
GARRIDO, Celso (1998): "El liderazgo de las grandes empresas industriales mexicanas" en PERES, W. (coord.), Grandes empresas y grupos industriales latinoamericanos, México, Siglo XXI-CEPAL, pp. 397-472.

-(1999): "El caso mexicano" en CHUDNOVSKY, D.; KOSACOFF, B. y LÓPEZ, A. (eds.), Las multinacionales latinoamericanas, México, FCE, pp. 165-258.

GIACALONE, Rita (2004): La regionalización del acero en América Latina, Buenos Aires, Biblos.

GRUPO INDUSTRIAL ALFA, S. A. (1985): Informe Anual 1984, Monterrey.

GUZMÁN, Alenka (2002): Las fuentes del crecimiento en la siderurgia mexicana, México, UAM.

HALASZ, Robert (1994): “Alfa Group, S.A. de C.V.”, www.answers.com/topic/ grupo-industrial-alfa, August 25.

HOSHINO, Taeko (1993): “The Alpha Group”, The Developing Economies, Vol. 31, n 4 (December), pp. 511-534.

HYLSAMEX (1999): Reporte Anual, www.hylsamex.com.mx.

-(2001): "Redefining our business portfolio", Reporte Annual, www.hylsamex.com.mx. HYLSAMEX, S.A. DE C.V. (2000): “Company Profile, Information, Business Description, History, Background Information on Hylsamex", www.referenceforbusiness.com.

ILAFA (2004): La Siderurgia de América Latina en Cifras 2004, Santiago de Chile, ILAFA.

INEGI (1997): Estadísticas Anuales, México.

-(1998): Estadísticas Anuales, México.

KOIKE, Kenji (1993): "Introduction", The Developing Economies, Vol. XXXI, n. 4 (December), pp. 363-378.

KÖLL, Elisabeth (2000): "Recent Debates in the Field of Business History", Chinese Business History, Volume 10, n. 1 (Spring), pp. 1-12.

KUSTER, Ted (1997): “AHMSA and Hylsa Aim for Exports and Added Value”, New Steel, (November), pp. 9-10.

LEAL GARCÍA, Alba (1998) "Pioneros del siglo xx", Expansión (México), 17/06/1998. -(2001): Expansión, (México), 31/03/2001.

LIJPHAR, Arend (1988): “The Comparable-Case Strategy in Comparative Research" en CANTORI, L. J. y ZIEGLER, A. H. (eds.), Comparative Politics in the PostBehavioral Era, Boulder, Colorado, Lynne Rienner, pp. 54-71.

LUSSANA, Carolina (1999): 1946: la prima frontiera, Bergamo, Fondazione Dalmine.

LUSSANA, Carolina y TONALINI, Manuel (2005): “Compagnia tecnica internazionale" en Techint 1945-1980, Bergamo, Fondazione Dalmine, pp. 21-113.

MCCRAW, Thomas (1988): "Introduction: The Intellectual Odyssey of Alfred D. Chandler, Jr." en MCCRAW, T. (ed.), The Essential Alfred Chandler, Boston, Harvard Business School Press, pp. 1-21. 
MAJUL, Luis (1992): Los dueños de la Argentina, 2 Tomos, Buenos Aires, Sudamericana.

MILESI, Darío, NOVICK, Marta y YOGUEL, Gabriel (2004): “Tramas productivas y desarrollo de ventajas competitivas", Boletín Informativo Techint, 314 (mayoagosto), pp. 45-72.

NUDLER, Julio (1999): “Los reyes del lobby", Página 12, 31/07/1999, p. 8.

OSTIGUY, Pierre (1990): Los capitanes de la industria, Buenos Aires, Legasa.

PORTER, Michael (1991): La ventaja competitiva de las naciones, Buenos Aires, José Vergara Editor.

POZAS, María de Los Angeles (1997): “Competitividad emergente y capital internacional", Congreso Internacional de LASA, Guadalajara, México, abril 17-19.

POZAS, María de los Angeles (1993): Industrial Restructuring in Mexico, San Diego, Center for U.S.-Mexican Studies, University of California, Monograph Series, 38.

PUGA, Cristina (1993): Empresarios y poder, México: Facultad de Ciencias Políticas y Sociales-UNAM.

ROCCA, Roberto y SZAPIRO, Susana (1995): “Hacia la articulación de un nuevo pensamiento industrial en la Argentina", en Boletín Informativo Techint 295 (julioseptiembre), pp. 11-31.

ROCCA, Roberto (1998): “El futuro de la industria argentina" Boletín Informativo Techint 295 (julio-septiembre), pp. 33-44.

RUEDA PEIRÓ, Isabel (1994) (coord.): Tras las huellas de la privatización, México, Siglo XXI.

SALAS-PORRAS, Alejandra (1998): “Estrategias de las empresas mexicanas en sus procesos de internacionalización” Revista de la CEPAL 65 (agosto), pp. 133-153.

SCHVARZER, Jorge (1996): La industria que supimos conseguir, Buenos Aires, Planeta.

SKOCPOL, Theda y SOMERS, Margaret (1994): “The uses of comparative history in macrosocial inquiry" en SKOCPOL, Theda (ed.), Social Revolutions in the Modern World, Cambridge, Cambridge University Press, pp. 72-95.

SNODGRASS, Warren (1992): “Free Trade and Mexican Steel”, Hemisphere, Vol. 4, n. ${ }^{\circ} 2$ (Winter/Spring), pp. 8-10.

STOK, Gustavo (2005): “Comprador compulsivo", América Economía, 19, 23/06/2005, pp. 32-33.

THOMSON, Eduardo (2008): “Todo en familia", www.americaeconomia.com, (Newsletter), 23/07/2008.

TOLEDO BELTRÁN, Daniel y ZAPATA, Francisco (1999): Acero y Estado. Una historia de la industria siderúrgica integrada de México, 2 Tomos, México, UAM.

TORRES, Ivette (2001): “The Mineral Industry of Mexico”, www.minerals.usgs.gov. minerals/pubs / country/2001/mxmyb01.

WILLIAMSON, Oliver (2005): “Business History and the Economics of Organization” Berkeley, California. 